\title{
Um caso de syndromo de Millard-Gubler
}

\author{
Trabalho apresentado á Sociedade \\ Arnaldo Vieira de Carvalho pelo \\ doutorando Edgard pinto Cezar.
}

SENDO convidado por alguns membros da directoria desta sociedade para apresentar nesta secção, um trabalho, accedi logo ao honroso convite, compromettendo-me a trazer alguma cousa que pudesse ser recebida nesta sociedade com algum interesse.

Entretanto vi-me logo apóz em serias difficuldades, não achando na occasião um assumpto que pudesse desenvolver e que estivesse nas alturas de ser aqui apresentado.

Felizmente, devido á bondade de nosso prezado mestre, Prof Ovidio Pires de Campos, pudemos dar desempenho a essa incumbencia, si bem que de maneira muito modesta, pelo que peço a condecendencia dos presentes e desculpas pelas faltas provavelmente numerosas que neste trabalho notarão.

Desde já peço que sejam inteiramente resalvadas as responsabilidades do mestre e seus illustres auxiliares, nas faltas que neste trabalho houver, faltas estas que correrão por minha responsabilidade, tendo sido este trabalho feito sem o visto delles.

E' o presente caso um d'aquelles que bem mostram a exactidão da semeologia nervosa, permittindo um diagnostico de localisação da lesão, perfeitamente baseado em dados seguros e creio que irrefuctaveis, salvo melhor juizo de algum membro desta sociedade.

Façamos em primero lugar a leitura da observação do nosso doente.

A. H., com 25 annos, casado, residente nesta capital.

Ant. hered: - Pae falleceu repentinamente, não sabendo de que. A mãe por uma molestia febril que começou pelo seios, evoluindo para a morte em uns 15 dias. $O$ casal teve 7 filhos dos quaes um falleceu ainda creança e outro aos 35 annos, neste Hospital, tendo ficado paralytico. Os outros são fortes. Não tiveram nati-mortos mas não sabe informar si houve abortos.

Ant. pessoaes: - Diz ter sido sempre forte, negando mesmo as molestias peculiares á infancia. A primeira vez que adoeceu foi esta. 
Nega contagios venereos e syphiliticos: bebia moderadamente e não fumava.

Historia pregressa da molestia actual: Em 15 de Janeiro do corrente anno, começou a sentir os primeiros prodromos de sua actual molestia. Sentia uma molesa geral pelo corpo que quasi o impossibilitava de trabalhar. Uns 5 dias depois, á noite percebeu que bruscamente sua boca virava para a direita e que seus dentes rangiram nessa occasião. Logo a seguir, perdeu a consciencia completamente, ficando assim uns 5 dias em sua casa, sendo depois removido para este Hospital, onde entrou em 25 de Janeiro p. p. sendo alojado na 3. ${ }^{a} \mathrm{M}$. H. onde o encontramos, já depois de ter sahido do estado comotoso em que esteve.

Passou ainda desaccordado muitos dias, sendo visitado varias vezes por sua mulher, sem que disso tivesse consciencia. Aos poucos foi melhorando e de varios dias para cá acha-se inteiramente bom sob o ponto de vista mental, respondendo com muita precisão todas ás nossas perguntas. Logo que voltou a si percebeu que estava paralytico de metade direita do corpo e com o rosto repuchado para o mesmo lado. Foi nesse estado que o encontramos.

Ex. somatico: - Trata-se de um moço, de bôa constituição esqueletica e muscular, com panicula adiposa desenvolvida. Pela inspecção geral notamos a asymetria facial, com augmento da rima palpebral do lado esquerdo, e apagamento completo dos sulcos do rosto, em nitido contraste com o lado opposto.

Apresenta-se em decubitus dorsal, com os membros inferiores bem extendidos.

Ganglios epitrocleanos pequenos de ambos os lados; a pleiade dos inguinaes está bem infarctada; ligeira esternalgia sem que apresente tibialgia.

App. resp: - Thorax bem desenvolvido, nada de anormal apresentando pela inspeç̧ão. Focetas supra e infra-claviculares pouco accentuadas. Pela percussão, palpação e auculta, nada de importante.

App. circulatorio: - Ictus no $5 .^{\circ}$ espaço, um pouco para fora da linha mamillar. Pela inspecção da região precardiaca nada ha de anormal. A' palpação sentimos que o choque da ponta é globoso fazendo-se sentir em tres tempos. Nada mais se percebe pela palpação. Pela auscultação do foco aortico verificamos que existe uma hyperphonese da $2 .^{a}$ bulha aortica ao mesmo tempo que um sopro fraco, doce e aspirativo ahi é audivel, propagando-se por toda a linha medio-esternal, sendo mesmo audivel na região medio-cardiaca. Na ponta notamos um esboço de ruido de galope (Potain) e um fraco sopro systolico, com pequena propagação para a axilla. No pulmonar só ha uma accentuação da $2 .^{a}$ fulha, com timbre metalico. No trisuspede ha a notar somente uma accentuação da $2 .^{\mathrm{a}}$ bulha, provavelmente de propagação do que se passa no foco aortico. Pela percussão, verifica-se que pequena é a alteração de volume do coração. 
No pescoço ha ligeiros batimentos vasculares e na furcula esternal sente-se os batimentos aorticos. A massicez pre-aortica parece estar um pouco augmentada principalmente para a esquerda. Não ha signal de Oliver-Cardarelli, nem differença dos pulsos radiaes. Tambem não se manifesta o duplo sopro crural de Alvarenga - Durozier, nem o pulso capillar de Quinque. Pulso radial, cheio, hypertenso, duro, batendo rythmadamente 90 vezes por minuto. Pressão arterial na humeral: $\max .19$ : $\min .13$.

App. digestivo: - Nada digno de nota.

Figado em seus limites normaes. Baço palpavel, de consistencia macia, attingindo o rebordo costal. Entretanto nosso doente não teve paludismo ou outra qualquer molestia que pudesse explicar o augmento desse orgão.

App. genito-urinario: - Orgãos genitaes bem desenvolvidos com caracteres sexuaes secundarios bem nitidos. Diz que depois de sua actual molestia, não teve mais erecções, sendo deste notar que anteriormente exercia as suas funç̧ões genitaes com toda a regularidade.

A miç̧ão é regular e nunca notou aspecto anormal na urina.

Exame neurologico: - Já pela simples inspecção do doente nos fere logo a vista a accentuada asymetria facil, com desvio da bocca para a direita e grande augmento da rima palpebral do olho esquerdo. Ao mesmo tempo queixa o paciente de estar com os membros do lado direito paralytico, só conseguindo fazer alguns movimentos com grande esforço.

Logo ao primeiro exame scientifica-se que a asymetria facial corre por conta de uma paralysia do VII por craneo esquerdo, affectando todos os territorios enervados por esse nervo, isto é, o facial inferior e superior, como mostrarei logo a seguir.

Assim é que vemos, na hemiface esquerda, o desapparecimento completo dos sulcos da face, parecendo ser o doente portador de uma meia mascara, em nitido contraste com a direita.

O sulco nazo-geniano está apagado; ha um ligero desvio do nariz para a direita. O doente não consegue enrugar a fronte do lado ésquerdo, os sulcos frontaes sendo á direita bem nitidos. A bocca é desviado para a direita. Estes signaes todos que logo notamos ao primeiro exame, mais ainda se accentuam quando provocamos os movimentos da mimica facil. O olho esquerdo, largamente aberto, não soffre occlusão completa quando o doente tenta fechal-o, em nitido contraste com o lado direito.

A falla está prejudicada principalmente na pronuncia de certas syllabas labiaes. O assobiar lhe é inteiramente impossivel.

Quando o doente contrahe o orbicular dos labios, o lado esquerdo não offerece resistencia quando tentamos eleval-o (signal de Mingazine). O mesmo é verificado com o orbicular das palpebras á esquerda (signal de Legendra). Quando o doente fecha os olhos, notamos a rotação para cima e para fóra do globo occular esquerdo (sig- 
nal de Negro. Abolição do reflexo nazo-ocular á esquerda (sig. de Dupuy - Cestan - Dutemps). Quando o paciente mastiga o alimento se accumula entre as gengivas e a bochecha esquerda (sig. de Guillain). A' esquerda notamos ainda a paralysia do musculo elevador da aza do nariz.

O signal da "epiphora" é pouco accentuado mas verificavel á esquerda. A "lagophtalmia" tambem não é muito intensa mas assim mesmo facilmente constatavel. Mandando o doente executar movimentos com o maxillar inferior para verificar a contracção do cuticular do pescoço, notamos que ella se faz muito bem á direita mas é nulla á esquerda (signal de Babinski).

Não tem perturbação para o lado do ouvido.

Não tem perturbação da sensibilidade ao nivel da zona de Ramsay-Hunt (comp. do inter. de Wrisberg).

Não ha perturbações da secreção salivar ou lacrimal (corda do tympano e sympathico cervical).

Como vemos é indubitavel que houve uma paralysia do VII par do lado esquerdo, paralysia esta peripherica. Mais adeante procuraremos discutir a sede da lesão que o comprometteu.

Examinando os outros pares craneanos nada notamos de anormal. E' de se notar que a musculatura extrinseca e intrinseca dos globos occulares se acha integra de ambos os lados.

Queixa-se o doente de uma paralysia dos membros do lado direito, rotae bem, lado opposto ao em que seu pprocesso a paralysia facial.

Fazendo o exame dos reflexos, notamos que os tendinosos e periosteos se acham muito exaltados para o lado direito e vivos, si bem que em gráu muito menos accentuado, nos membros do lado esquerdo. Pesquizamos os achileanos, rotuleanos, tibifemural-posterior, peroneofemural posterior, o dos adductores que se faz sentir controlateral, e nos membros superiores o radial, o cubito-pronador, o biceptal, o triceptal e o oleraneano. Sempre notamos nitida desigualdade entre o lado direito e esquerdo, sendo d'aquelle muito mais exaltados. $\mathrm{O}$ reflexo de Mendel-Bechterew se faz em flexão dorsal de ambos os lados.

Pesquizando os reflexos cutaneos constatamos que o cutaneo plantar se faz em extensão dorsal para o grande artelho (signal de Babinski), isso de ambos os lados, si bem que muito mais nitido para a direita. O cremasterino é vivo á esquerda e ausente á direita. O mesmo com o reflexo gluteo. Os abdominaes são vivos á esquerda e quasi imperceptiveis á direita.

Ha clonus do pé e da rotula, de ambos os lados, sendo um clonus frusto á esquerda e bem accentuado á direita. A força muscular está muito diminuida á direita e mais ou menos normal á esquerda.

Contractura não é observavel na execução dos movimentos passivos.

A marcha é difficil pela grande perda de força da perna direita. Apoiado o doente consegue andar e então nota-se que ella se faz 
"ceifante" com a perna direita. Quando consegue andar sem apoio, notamos a perda dos movimentos associados do braço direito em contraste com o que se verifica á esquerda.

Não ha tremores ou outro qualquer movimento involuntario.

Do lado direito facilmente provocamos reflexo de defeza pelas manobras usuaes.

Levantando as pernas do paciente a um mesmo nivel acima do leito, e deixando-as cahir, verificamos que a do lado direito cahe pesadamente, como um corpo iierte, ao passo que do lado opposto o faz instantes depois, e lentamente, sustida que é pela força muscular.

Fazendo o exame da sensibilidade, bem interessantes foram as nossas verificações. Assim notamos que ha um compromettimento accentuado de quasi todas as modalidades de sensibilidades, conscientes quer superficiaes quer profundas. A sensibilidade thermica, tactil, e dolorosa estão bem affectadas em toda a metade direita do corpo, desde a cabeça até os pés. Das sensibilidades profundas verificamos serio compromettimento do sentido estereognosico, sensação das attitudes segmentares e sensibilidade ossea. Todas ellas em toda a metade direita do corpo, estando integras no lado opposto. A sensibilidade tendinosa e testicular nos parecem normal de ambos os lados.

Os reflexos pupillares á luz, á acommodação e consensual se fazem normalmente de ambos os lados. Os movimentos occulares são bem executados e não ha ninstagmus.

Devemos anda assignalar que actualmente $o$ doente consegue executar movimentos com os membros do lado direito. Nestas condições nos foi possivel fazer executar manobras para a pesquiza de signaes cerebelares, tendo verificado a adiadococynesia e hypermetria do lado esquerdo. Não notamos outros signaes da serie verebellosa.

Logo apoz a. sua entrada foi feita a puncção lombar para a extracção do liquido cephalo-rarchideano onde se procedeu á reacção de Wassermann que deu resultado negativo. O liquido retirado apresentava uma coloração amarellada (xantochromia). A reaçãa de Wassermann no sangue, feita por duas vezes deu resultado negativo.

No mesmo dia do entrado foi feita uma sangria, sendo retirado 450 c. c. de sangue. A dosagem da urea no sôro sanguineo deu 0,gr.999 por litro.

O exame de urina revelou traços evidentes de albumina e nada mais digno da nota.

Devemos frisar que o doente tem melhorado consideravelmente nestes ultimos dias, desapparecendo muitos signaes que antes foram facilmente verificaveis. Assim é que para o lado cardiaco não mais notamos o sopro diastolico do foco aortico, ssó permanecendo o pequeno sopro systolico da ponta.

Quanto ás perturbações do seu systhema nervoso vimos que as manifestações de pyramidalismo do lado esquerdo desappareceram 
quasi todas, só restando uma certa exaltação do reflexos tendinosos. Não mais se faz sentir o clonus do pé e da rotula e nem mesmo o signal de Babinski que ahi tão facilmente era encontrado.

Do lado direito o clonus do pé já se faz sentir muito pouco, sendo um clonu frusto e só apparece quando o doente anda ou depois de provocado por varias vezes. O da rotula tambem se faz sentir com pouco intensidade. Em compensação o signal de Babinski é muito nitido assim como a exaltação dos reflexos tendinosos e periosteos.

Para o lado da face, já consegue o doente fechar mais a palpebra esquerda, mas este movimento é ainda defficiente. Não ha mais a lagophtalmia.

\section{I S CUSS Ã O}

Diante do quadro exposto vemos que se trata de um doente affectado de varias manifestações em varios apparelhos e que convem descutidas.

Em primeiro lugar vimos as perturbações cardiacas; pequeno sopro aortico, diastolico, que desappareceu com o repouso. Pequeno sopro mitral que ainda hoje se mantem. - Poderemos dahi concluir que haja uma lesão das valvulas aorticas? Creio que não. Parece-me mais acertado dizer que se tratava de uma insufficiencia aortica funccional, por relaxamento do annel muscular do infundibulo aortico. Quanto ao sopro mitral, não podemos affirmar de que natureza é, nos parecendo entretanto ser uma lesão semelhante, pois não encontramos em nosso paciente um passado morbido que nos autorise a crer numa lesão valvular de natureza infecciosa e a natureza do sopro não nos permitte uma affirmativa.

A hyperphonese da $2 .{ }^{\mathrm{a}}$ bulha aortica corre por conta da grande hypertensão arterial de que é soffredor.

Pelo ruido de galope que hoje quasi não se percebe, pela hypertenção e pela dosagem da urea no sangue, creio poder affirmar que o doente é um renal ou mesmo um cardio-renal ainda pouco adeantado. Sua nephrite, uremigenica e hypertensiva.

Resta-nos agora discutir a questão mais importante em nosso caso, a que lhe dá maior interesse: a lesão de seu systhema nervoso.

Como vemos pelo exposto, o doente em um ictus ficou alguns dias em estado de coma e depois apresentou-se com uma paralysia do VII par craneano do lado esquerdo, paralysia do typo periferico, e uma hemiplegia e hemianesthesia do lado opposto.

Trata-se portanto de um syndromo paralytico alterno.

Uma vez visto isso, resta-nos saber qual foi a natureza da lesão, qual a sua causa e finalmente, qual a sua séde.

Quanto á natureza da lesão creio ser hemorragica. A isto sou levado pelo facto de ser um doente moço, por ter surgido em um ictus 
subito, sem prodromos e pelo aspecto do liquido cephalo rachideano. Neste não foram feitos alguns exames importantes que mais poderiam provar a naturesa da lesão, constitundo isto uma das certamente numerosas falhas da nossa observação.

A causa desta hemorragia podemos attribuir á grande hypertensão arterial. Quanto á possibilidade de haver uma arterite syphilitica, não possuimos dados quie nos autorise mais que uma simples suspeita. Como vimos as reacções de Wasserman procedidas no liquido cephalo-rachideano no sangue, foram inteiramente negativos Bem sabemos que isto não constitue uma prova conveniente para affastar a hypothese formulada.

As outras reacções, que poderiam ser feitas no liquido cephalorachideano, e que muito ajudariam o diagnostico, tambem não foram procedidas, sendo esta mais uma falha a ser assignalada.

Quanto a séde da lesão, eis aqui a parte mais interessante sob o ponto de vista neurologico.

Onde poderia estar situada uma lesão para ao mesmo tempo lesar o VII par do lado esquerdo, dar uma hemiplegia dos membros do lado direito e ainda um compromettimento de quasi todas as formas de sensibilidade consciente do mesmo lado da hemiplegia?

Como vemos pelo exposto, trata-se de um caso de hemiplegia alterna.

Passemos uma rapida revista aos diversos syndromos alternos para vermos onde poderemos enquadrar o nosso caso.

Uma hemiplegia alterna peduncular não é possivel que seja. Sabemos que nestes casos a ophtalmoplegia é a regra, dando os syndromos de Weber quando affecta a parte anterior do pedunculo e paralysia do facial inferior somente, o que contrasta nitidamente com o nosso caso. Além disso não vemos compromettimento do hypoglosso que é a regra.

Syndromo peduncular posterior ou de Benedicte tambem não pode. ser, faltando quasi todos os seus elementos em nosso caso.

Será um syndromo protuberancial?

Eis o que mais nos parece. Entretanto nosso caso não é o de um syndromo de Millard-Gubler completo. Nelle não vemos a paralysia o VI par junto á do VII e do mesmo lado que este. Além disso vemos que ha uma hemianesthesia affectando quasi todas as formas de sensibilidade, o que é proprio de uma syndromo protuberancial posterior, pois é nessa parte da protuberancia que se acha a fita de Reill. Portanto neste nosso caso seria lesão affectando ambas as partes da protuberancia, anterior e posterior.

Outro syndromo como o de Faville e os bulbares nem queremos passar em revista por não se poderem assemelhar ao que se passa em nosso caso.

Si o syndromo de Millard-Gubler não e typico por falta da paralysia do VI par, esta falta não implica na refutação do diagnostico. Assim vemos que Claude diz que o syndromo em questão 
"se caracterisa pela paralysia da face de um lado e dos membros do lado opposto" Diz mais adeante que "a paralysia do VI par póde se ajuntar á do VII e póde mesmo existir só, em lugar da paralysia facial"

Creio que não póde haver duvida de que a lesão se assesta no lado esquerdo da protuberancia, ahi affectando o facial, o feixe pyramydal antes de seu entrecruzamento e a fita de Reill tambem antes de se entrecruzar.

E' este o meu diagnostico.

LABORATORIO DE MICROSCOPIA

E ANALYSES

CLINICAS

\section{Dr Altino Antunes}

RUA DO CARMO N. 11 TELEPHONE 2463 (CENTRAL) SÃO PAULO 